\title{
Self-shape optimisation application: Optimisation of cold-formed steel columns
}

\author{
Benoit. P. Gilbert ${ }^{(1)}$, Timothee J.-M. Savoyat ${ }^{(2)}$, Lip H. Teh ${ }^{(3)}$ \\ (1) Lecturer, Griffith School of Engineering, Gold Coast Campus, Griffith University, QLD 4222, Australia, \\ Email: b.gilbert@griffith.edu.au, Phone: +61 755528577 (corresponding author) \\ (2) Former exchange undergraduate student, Griffith School of Engineering, Gold Coast Campus, Griffith \\ University, QLD 4222, Australia \\ (3) Senior Lecturer, School of Civil, Mining and Environmental Engineering, University of Wollongong, NSW \\ 2522, Australia, Email: Iteh@uow.edu.au
}

\section{ABSTRACT}

This paper presents the optimisation of cold-formed steel open columns using the recently developed self-shape optimisation method that aims to discover new profile shapes. The strength of the cold-formed steel sections is calculated using the Direct Strength Method, and the rules developed in the present work to automatically determine the local and distortional elastic buckling stresses from the Finite Strip and constrained Finite Strip Methods are discussed. The rules are verified against conventional and optimum sections yielded in this research, and found to accurately predict the elastic buckling stresses. The optimisation method is applied to singly-symmetric (monosymmetric) cold-formed steel columns, and the operators behind the method for the special case of singly-symmetric open profiles are introduced in this paper. "Optimum" cross-sections for simply supported columns, $1.2 \mathrm{~mm}$ thick, free to warp and subjected to a compressive axial load of $75 \mathrm{kN}$ are presented for column lengths ranging from $1,000 \mathrm{~mm}$ to $2,500 \mathrm{~mm}$. Results show that the optimum cross-sections are found in a relatively low number of generations, and typically shape to non-conventional "bean", "oval" or rounded " $\Sigma$ " sections. The algorithm optimises for distortional and global buckling, therefore likely subjecting the cross-sections to buckling interaction. A manual attempt to redraw the "optimum" cross-sections to include limitations of current manufacturing processes is made. Future developments of the method for practical applications are also discussed. 


\section{KEYWORDS}

Self-shape optimisation, Light gauge steel, Direct Strength Method, Cold-formed steel columns 


\section{INTRODUCTION}

Cold-formed steel columns are widely used in the construction industry due to their lightweight, easy installation and erection, and economy. The strength and efficiency of cold-formed steel profiles depends on the cross-sectional shape, which controls the three fundamental buckling modes: local, distortional and global. Despite the manufacturing process allowing achievement of almost any desired cross-sections, only conventional $\mathrm{C}, \mathrm{Z}$ or $\Sigma$ cross-sectional shapes are normally used in practice. Very few researches aim at optimising the cross-sectional shape itself, as detailed in the literature review on shape optimisation in [1].

This paper aims to extend the self-shape optimisation principles described in the companion paper [1], and detailed in [2], to the strength optimisation of cold-formed steel columns. In the present case, the member capacity depends not only on the second moments of area, but also on the slenderness with respect to global, local and distortional buckling modes. There are no direct closed form equations for determining the member capacity accounting for these buckling modes, and the Direct Strength Method (DSM) is introduced in the algorithm.

Automatic determination of the elastic buckling stresses of cold-formed steel profiles for optimisation purposes is challenging as "engineering judgement" is often needed to select the appropriate buckling value when elastic buckling analyses fail to directly identify a mode. This paper presents a clear set of rules to obtain the local and distortional elastic buckling stresses using the Finite Strip Method (FSM) [3-5] and constrained Finite Strip Method (cFSM) [6-9]. The rules are verified against conventional and "optimum" cross-sections yielded in the present work, and are found to accurately predict the elastic buckling stresses.

The operators that allow the cross-section to self-shape to an "optimum" profile are presented for singly-symmetric (mono-symmetric) open cross-sections, and columns of lengths varying from $1,000 \mathrm{~mm}$ to $2,500 \mathrm{~mm}$ are optimised for a targeted compressive axial capacity of $75 \mathrm{kN}$. The 
optimum cross-sectional shapes found in the present work are discussed with respect to their shape, dimensions, critical buckling modes and buckling mode interactions.

A manual attempt to redraw the "optimum" cross-sections to include the current limitations of cold-forming processes is made. Future developments of the method are discussed.

\section{OPTIMISATION PROBLEM}

The present optimisation problem is illustrated in Figure 1 and is concerned with minimising the cross-sectional area $A$ of a column subjected to an axial compressive load $N^{*}$ of $75 \mathrm{kN}$. The column is composed of $1.2 \mathrm{~mm}$ thick cold-formed steel open section, and is free to warp at the supports. The yield stress $f_{y}$ is $450 \mathrm{MPa}$, the Young's modulus $E$ is $200 \mathrm{GPa}$ and the shear modulus $G$ is 77 GPa. Buckling lengths ranging from $1,000 \mathrm{~mm}$ to $2,500 \mathrm{~mm}$ are included in the present study.

The unconstrained optimisation problem suitable for GA consists of minimising the "fitness function" $f$ as,

$$
\text { Minimise } f=\frac{A}{A_{\text {squash }}}+\alpha\left|\frac{N^{*}}{N_{c}}-1\right|
$$

where $N_{c}$ represents the nominal axial capacity of the column (automatic determination of $N_{c}$ for is

discussed in Section 3), the parameter $\alpha$ is a penalty factor, and $A_{\text {squash }}$ represents the lower bound cross-sectional area of the profile, defined as,

$$
A_{\text {squash }}=\frac{N^{*}}{f_{y}}
$$




\section{AUTOMATIC DETERMINATION OF THE NOMINAL AXIAL COMPRESSION CAPACITY $N_{C}$ USING THE DSM}

\subsection{The Direct Strength Method for columns}

In order to estimate the nominal axial compression capacity $N_{c}$ of the column in Eq. (1), the Australian design standard AS/NZS 4600 Cold-formed Steel Structures [10] is used in the present work. The standard allows the determination of the axial capacity using two distinct methods, referred to as the "Effective Width Method" (EWM) and the "Direct Strength Method" (DSM). The DSM, developed by Schafer and Pekoz [11], looks at the entire member rather than individual elements as in the EWM and has the advantages of offering the same design simplicity for complex and simple sections. Its recent development for the design of cold-formed steel sections [12, 13] has simplified the design procedure when compared to earlier methods based on the EWM [10, 14 , 15]. More importantly, it allows a more direct route to section optimisation as the three fundamental buckling modes (local, distortional, and global) are now represented by direct strength equations thus allowing the GA to operate with a more clearly defined set of constraints. This was not possible previously [16].

In the DSM, the global, local and distortional axial member capacities, $N_{c e}, N_{c l}$ and $N_{c d}$ respectively, are determined, and the nominal member capacity in compression $N_{c}$ is equal to the lowest of them

$$
N_{c}=\min \left(N_{c e}, N_{c l}, N_{c d}\right)
$$

\subsubsection{Flexural, torsional or flexural-torsional member capacity $N_{c e}$ in the DSM}

The global buckling mode does not involve change in the cross-sectional shape, but translation (flexure) and/or rotation (torsion) of the entire cross-section. For singly-symmetric open crosssection, the columns will either fail in "flexural" or "flexural-torsional" buckling. The DSM specified in 
AS/NZS 4600 [10] calculates the nominal capacity $N_{c e}$ for global buckling based on the nondimensional slenderness ratio $\lambda_{c}=\sqrt{N_{y} / N_{o c}}$ as,

$$
\begin{array}{ll}
\text { For } \lambda_{c} \leq 1.5: & N_{c e}=\left(0.658^{\lambda_{c}^{2}}\right) N_{y} \\
\text { For } \lambda_{c}>1.5: & N_{c e}=\left(\frac{0.877}{\lambda_{c}^{2}}\right) N_{y}
\end{array}
$$

where $N_{o c}$ is the elastic global buckling load taken as,

$$
N_{o c}=A f_{o c}
$$

and $N_{y}$ is the nominal yield capacity defined as,

$$
N_{y}=A f_{y}
$$

$A$ is the gross cross-sectional area and $f_{o c}$ is the elastic global buckling stress.

In this study, the elastic global buckling stress $f_{o c}$ is determined using Timoshenko's buckling theory as given in Clause 3.4 .3 of AS/NZS 4600 [10]. For singly-symmetric open cross-sections, where $x$ is the axis of symmetry, $y$ is the axis perpendicular to the axis of symmetry and $z$ is the member axis, $f_{o c}$ is given as,

$$
f_{o c}=\min \left(f_{o x z}, f_{o y}\right)
$$

where $f_{o x z}$ is the elastic flexural-torsional buckling stress and $f_{o y}$ is the elastic flexural buckling stress about the axis perpendicular to the axis of symmetry.

\subsubsection{Local member capacity $N_{c l}$ in the DSM}

Local buckling involves a change in the cross-sectional shape and includes only rotation, not translation, at the fold lines (e.g. the corners of a plain channel section) [13]. The DSM specified in AS/NZS 4600 [10] accounts for the interaction between local and global buckling, and calculates the nominal capacity $N_{c l}$ for local buckling based on the non-dimensional slenderness ratio $\lambda_{I}=$ $\sqrt{N_{c e} / N_{o l}}$ as, 
For $\lambda_{1} \leq 0.776$ :

$$
N_{c l}=N_{c e}
$$

$$
\text { For } \lambda_{l}>0.776: \quad N_{c l}=\left[1-0.15\left(\frac{N_{o l}}{N_{c e}}\right)^{0.4}\right]\left(\frac{N_{o l}}{N_{c e}}\right)^{0.4} N_{c e}
$$

where $N_{o l}$ is the elastic local buckling load taken as,

$$
N_{o l}=A f_{o l}
$$

and $f_{o l}$ is the elastic local buckling stress. The determination of $f_{o l}$ is discussed in Section 3.2.3.

\subsubsection{Distortional member capacity $N_{c d}$ in the DSM}

Distortional buckling involves distortion of the cross-section, which includes translation and rotation at one or more fold lines. The half-wavelength falls between local and global buckling [13]. The DSM specified in AS/NZS 4600 [10] calculates the nominal column capacity $N_{c d}$ for distortional buckling based on the non-dimensional slenderness ratio $\lambda_{d}=\sqrt{N_{y} / N_{o d}}$ as,

$$
\begin{array}{cc}
\text { For } \lambda_{d} \leq 0.561: & N_{c d}=N_{y} \\
\text { For } \lambda_{d}>0.561: & N_{c d}=\left[1-0.25\left(\frac{N_{o d}}{N_{y}}\right)^{0.6}\right]\left(\frac{N_{o d}}{N_{y}}\right)^{0.6} N_{y}
\end{array}
$$

where $N_{o d}$ is the elastic distortional buckling load taken as,

$$
N_{o d}=A f_{o d}
$$

and $f_{o d}$ is the elastic distortional buckling stress. The determination of $f_{o d}$ is discussed in Section 3.2.4

\subsubsection{Current research to enhance the DSM}

Research is currently undertaken to account for interactions between buckling modes other than local and global buckling [17-25]. However, further investigation is needed to completely consider these interactions for practical design, and the DSM as adopted in Clause 7 of AS/NZS 4600 [10] is 
adopted in this study. However, the present optimisation procedure is anticipated to consider all buckling mode interactions when these phenomena are fully incorporated in the DSM. A discussion of buckling mode interactions for the "optimum" cross-sections found in this study is given in Section 6.1 .

\subsection{Elastic buckling stresses}

\subsubsection{General}

As shown in Sections 3.1.1 to 3.1.3, the elastic global, local and distortional buckling stresses $f_{o c}$, $f_{o l}$ and $f_{o d}$, respectively, are needed to calculate the global, local and distortional member capacities $N_{c e}, N_{c l}$ and $N_{c d}$, respectively. The elastic global buckling stress $f_{o c}$ can be estimated by either the Finite Strip Method (FSM) [3-5] or Timoshenko's buckling theory, whereas the elastic local and distortional buckling stresses $f_{o l}$ and $f_{o d}$ are typically estimated using the FSM.

A Finite Strip analysis provides a buckling curve, also referred to as the "signature curve", of the buckling stresses against the half-wavelength with the associated buckling modes. Figure 2 shows the buckling curve obtained from a Finite Strip analysis of a $90 \mathrm{~mm}$ deep, $50 \mathrm{~mm}$ wide and $1.2 \mathrm{~mm}$ thick lipped Cee section, referred to as C9012.

Ideally, a buckling curve, such as the one shown in Figure 2, has two minima corresponding to the elastic local (first minimum) and distortional (second minimum) buckling stresses. However, Finite Strip analyses often result in one or no local minimum, and fail to directly identify the local and/or distortional buckling stresses. Indistinct buckling modes can be manually identified as discussed in [13]. Yet, the recent development of the constrained Finite Strip Method (cFSM) [6-9] opened new possibilities in optimisation of cold-formed steel members by providing automatic identification of indistinct buckling modes [26]. The cFSM enables calculations of "pure" buckling modes [7] and separates buckling modes into four subspaces referred to as "global", "distortional", "local" and "other". The buckling curves for each "pure" mode can be calculated individually with the mode definitions adopted from the Generalised Beam Theory (GBT) [7]. The pure mode 
decompositions for distortional and local buckling using the cFSM are shown in Figure 2 for the C9012 lipped Cee section.

Currently, no clear set of proven rules exists to automatically determine the local and distortional elastic buckling stresses for shape optimisation. For general optimisation purposes, Schafer [26] recommends the use of the cFSM to determine the critical half-wavelengths from the "pure" modes (i.e. determining the half-wavelengths corresponding to the minimum of the "pure" mode buckling curves) in conjunction with the use of FSM to determine the buckling stresses. Additionally, Li and Shafer [27] advises to perform constrained Finite Strip analyses on straight-line models, ignoring the corners. The latter recommendation is however not suitable for shape optimisation purposes that typically generate rounded cross-sections, as shown in Section 5 and [28]. Alternatively, if the signature curve from a Finite Strip analysis has unique minima, the need for performing a constrained Finite Strip analysis may be avoided [27].

For shape optimisation purposes, Leng et. al. [28] only performed Finite Strip analyses and, if more than one local minimum exist on the buckling curve, chose the first local minimum of the buckling curve for $f_{o l}$ and the smallest of the remaining local minima, for $f_{o d}$. If only one local minimum exists, then this minimum is chosen for $f_{o l}$ if it occurs at a half-wavelength less than a reference length. Otherwise, the local minimum is chosen for $f_{o d}$. The reference half-wavelength is initially taken as the "perimeter length" and regularly updated through the optimisation process as the distortional critical half-wavelength when more than one local minimum exists. However, it is not clear if the method consistently determines the actual elastic buckling stresses, as if only one local minimum exists and is greater than the reference length, the algorithm is likely to overestimate the critical half-wavelength $L_{c r l}$ for local buckling. Conversely, if the local minimum occurs at a halfwavelength less than the reference, the critical half-wavelength $L_{c r d}$ for distortional buckling may be underestimated. 


\subsubsection{The use of the cFSM for local buckling and shape optimisation}

The calculation of the "pure" local buckling curve from the cFSM requires intermediate nodes, referred to as "sub-nodes", to be inserted between "main nodes". The main nodes are located at the intersection of two strips having a non-zero angle relative to each other [6]. Consecutive sub-nodes are therefore aligned and the plates are only able to buckle between main nodes.

Consequently, the cFSM for local buckling is well suited for cross-sections with straight lines and no rounded corners. For randomly drawn cross-sections where strips are likely to have non-zero angles relative to each other or for cross-sections with not perfectly flat sides, it is unclear which nodes have to be considered as sub-nodes. Moreover, it is likely that the transition from a sub-node to a main node is a gradual process, with sub-nodes partially preventing the plate to buckle between main nodes.

Currently, Finite Strip analysis programs, such CUFSM [29] used in this study, checks if three or more consecutive nodes are aligned, within a given tolerance, to make the distinction between subnodes and main nodes, and is likely to consider too many nodes as main nodes in the current optimisation process, give low critical half-wavelengths and therefore overestimate the local elastic buckling stress $f_{\text {ol. }}$. This statement is illustrated in [30] using two C9012 lipped Cee sections with one having misaligned nodes in the web by half the profile thickness. Finite Strip analyses of the two cross-sections show little difference in the buckling curve and both cross-sections have the same critical half-wavelength $L_{c r l}$ for local buckling at $72 \mathrm{~mm}$. However, a constrained Finite Strip analysis predicts the correct critical half-wavelength for local buckling at $72 \mathrm{~mm}$ for the "aligned" crosssection but results in a critical half-wavelength at $44 \mathrm{~mm}$ for the "misaligned" cross-section. The error in determining the critical half-wavelength results in the overestimation of the elastic local buckling stress by $50 \%$. See [30] for more details. Determining the critical local half-wavelength using cFSM is therefore not recommended for arbitrarily drawn or rounded cross-sections that have node misalignments, and the recommendation in $[26,27]$ described in the previous section cannot be used for local buckling and shape optimisation. 


\subsubsection{Proposed rule for determining the elastic local buckling stress $f_{o l}$}

The critical half-wavelength $L_{c r l}$ for local buckling for a member in compression is typically less than or equal to the largest outside dimension $d$ of the cross-section [13], and the elastic local buckling stress $f_{o l}$ would typically correspond to the minimum of the buckling curve at a halfwavelength lower than $d$. Therefore, following this observation, the elastic local buckling stress $f_{o l}$ of a cross-section is determined from the smallest local minimum, if it exists, or from the smallest gradient of the buckling curve, in the half-wavelength interval $\left[r_{0}, d\right]$, where $r_{0}$ is the least radius of gyration of the column.

\subsubsection{Proposed rule for determining the elastic distortional buckling stress $f_{\text {od }}$}

Distortional buckling occurs at a half-wavelength significantly greater than local buckling, typically between three and nine times the largest outside dimension $d$ of the cross-section [13]. Stub column tests do not generally pick up distortional buckling [31], and AS/NZS 4600 [10] recommends a maximum length for stub-column tests of twenty times the least radius of gyration $r_{0}$. Therefore, the literature shows that distortional buckling likely occurs at a half-wavelength between the lesser of $20 r_{0}$ and $3 d$, and $9 d$. However, verification of the present rules in Section 3.2.5 showed that a value of $10 d$ is a better upper limit for distortional buckling, and is adopted herein.

Following these observations and the recommendations by Schafer [26] discussed in Section 3.2.1, the half-wavelength $L_{c r d}$ for distortional buckling is determined using the cFSM in the halfwavelength interval [min $\left.\left(20 r_{0}, 3 d\right), 10 d\right]$, and the elastic buckling stress is then determined using the FSM. If more than one local minimum exist on the "pure" distortional buckling curve, the halfwavelength for distortional buckling is taken at the smallest local minimum.

It may be noted that local minimum may not always be found on the "pure" distortional buckling curve in the interval [min $\left.\left(20 r_{0}, 3 d\right), 10 d\right]$, and the search interval needs to be extended to an upper limit of $13 d[30]$. 


\subsubsection{Validation of the proposed rules}

The proposed set of rules for determining the elastic local and distortional buckling stresses is validated in this section against a manual method, subjected to engineering judgement and best practice for handling indistinct buckling modes, as discussed in [13]. If indistinct local mode occurs, options to determine the critical local half-wavelength $L_{c r l}$ include: (i) refining the half-wavelengths, (ii) basing judgement on the definition of the buckling mode given in Section 3.1.2, keeping in mind that local buckling should occur at a half-wavelength less than the largest outside dimension of the member in compression $d$, or (iii) if possible, pin internal fold lines to force local buckling. Similarly, if indistinct distortional mode occurs, options to determine the critical local half-wavelength $L_{c r d}$ include: (i) refining the half-wavelengths, (ii) basing judgement on the definition of the buckling mode given in Section 3.1.3, (iii) slightly varying the dimensions of the model to recognise a trend in distortional buckling minima or (iv) if possible, pin appropriate internal fold lines to force distortional buckling.

Forty eight conventional cross-sections and twelve "optimum" cross-sections, found in Section 5 , are used to validate and cross-validate, respectively, the proposed set of rules. Specifically, the following cross-sections are considered:

- 16 lipped Cee-sections and 16 lipped Zed-sections commonly used in Australia and manufactured by BlueScope Steel Lysaght [32], as shown in Figure 3. The nominal depth of the profiles ranges from $100 \mathrm{~mm}$ to $350 \mathrm{~mm}$, and the nominal wall thickness from $1.0 \mathrm{~mm}$ to $3.0 \mathrm{~mm}$.

- 16 typical storage rack uprights, including 9 profiles without lip stiffeners and 7 profiles with lip stiffeners, as shown in Figure 4. The nominal depth of the profiles ranges from $55 \mathrm{~mm}$ to $90 \mathrm{~mm}$ for the profiles without lip stiffeners, and from $55 \mathrm{~mm}$ to $110 \mathrm{~mm}$ for the profiles with the lip stiffeners. The nominal wall thickness ranges from $1.2 \mathrm{~mm}$ to $2.4 \mathrm{~mm}$. All $55 \mathrm{~mm}$ deep uprights have no web stiffener, as shown in Figure 4 (c-d), while all remaining uprights have one web stiffener, as shown in Figure 4 (a-b). 
- 12 "optimum" cross-sections found in Section 5, corresponding to the three fittest cross-sections for each of the four column lengths investigated.

Table 1 shows the average difference in determining the local and distortional elastic buckling stresses from the manual method and automated set of rules. Detailed results can be found in [30]. Table 1 shows that the two methods give similar results, with an average difference of less than $1 \%$ for all cross-sections analysed and for the two modes of buckling. The maximum difference is equal to $8.6 \%$ and is encountered for a $55 \mathrm{~mm}$ deep and $2.4 \mathrm{~mm}$ thick storage rack upright without lip stiffeners. The standard deviation in predicting the elastic buckling stresses between the two methods is equal to $1.6 \%$ and $1.9 \%$ for the local and distortional buckling, respectively.

Manually determining the critical half-wavelength for local buckling proved challenging for the optimum sections, as the first minimum on the buckling curve may occur at a half-wavelength between the typical values for local and distortional buckling (of about two times the largest outside dimension of the cross-section), as illustrated in Figure 5 for the three $2,500 \mathrm{~mm}$ long columns. These minima are likely to be disregarded by an engineer for local buckling, as occurring at a halfwavelength greater than $d[13]$, and $f_{o l}$ was therefore manually chosen at a lower half-wavelength herein based on the definition of the buckling mode given in Section 3.1.2.

For the "optimum" $1,000 \mathrm{~mm}$ long columns, only one minimum typically occurs on the buckling curve in the half-wavelength range for distortional buckling, but was not selected by the two methods, as the associated buckling mode is a combination of local and distortional buckling, as illustrated in Figure 6. 


\section{SELF-SHAPE OPTIMISATION PRINCIPLES FOR SINGLY-SYMMETRIC COLD- FORMED STEEL PROFILES}

\subsection{Initial population}

As described in the companion paper [1], initial cross-sections are generated using self-avoiding random walks. As the cross-sections of interest are singly-symmetric, only half of each crosssection is modelled in the optimisation process.

A design space of $100 \mathrm{~mm} \times 100 \mathrm{~mm}$ is used in generating the half cross-sections. This design space may represent imposed constraints for the depth and width of the profile, to a maximum of $200 \mathrm{~mm}$ and $100 \mathrm{~mm}$, respectively.

The cross-sectional areas of the initial population are deliberately generated to be uniformly distributed (see [2]) in five categories, for cross-sectional areas ranging from $A_{\text {ref }}-70 \mathrm{~mm}^{2}$ to $A_{\text {ref }}+$ $70 \mathrm{~mm}^{2}$; where $A_{\text {ref }}$ represents a reference value in the order of magnitude of the "optimum" crosssectional area. $A_{\text {ref }}$ is estimated for each column length by pre-running the algorithm with a large initial population of cross-sectional areas ranging from $A_{\text {squash }}$ to five times $A_{\text {squash. }}$ Values of $A_{\text {ref }}$ equal to $1.5 \times A_{\text {squash }}\left(250 \mathrm{~mm}^{2}\right), 1.75 \times A_{\text {squash }}\left(292 \mathrm{~mm}^{2}\right), 2 \times A_{\text {squash }}\left(333 \mathrm{~mm}^{2}\right)$ and $2.25 \times A_{\text {squash }}(375$ $\mathrm{mm}^{2}$ ) were found to produce a reasonable estimation of the "optimum" cross-sectional areas for the $1,000 \mathrm{~mm}, 1,500 \mathrm{~mm}, 2,000 \mathrm{~mm}$ and $2,500 \mathrm{~mm}$ long columns respectively.

As discussed in [1, 2], the element size shall be small enough to ensure the accuracy of the cross-sectional area and allow complex cross-sectional shapes, including stiffeners, to be drawn. A nominal element size of $4 \mathrm{~mm}$ (i.e. 3.33 times the thickness) was found to be a reasonable compromise between accuracy and computational time in this study.

Cross-sections are therefore drawn on the $x_{\max }=100 \mathrm{~mm} \times y_{\max }=100 \mathrm{~mm}$ design space, and the reference point at $\left(x_{\max } / 4,0\right)$ is chosen to be the origin of the cross-sections on the axis of symmetry. Similar steps to the ones presented in the companion paper [1] are used, with the 
exception that the cross-sections are drawn until they reach a predefined cross-sectional area corresponding to one of the five distributive categories. All steps are detailed in [30].

Initial cross-section examples are presented in Figure 7, where only half of the profile is drawn. The horizontal axis $x=0$ is the axis of symmetry.

\subsection{Cross-over operator}

The cross-over operator is similar to the one presented in the companion paper [1], with two points $P_{\text {parent1 }}$ and $P_{\text {parent2 }}$ chosen at $\delta \%$ along the length of the first and second parents, respectively, with $\delta$ being a random number in the open interval ]0,100[, so the first and last points of the parents are not selected. The two points $P_{1}$ and $P_{2}$ are defined using a linear interpolation between $P_{\text {parent1 }}$ and $P_{\text {parent2, }}$, as illustrated in Figure 8.

Two offsprings are created per operation with the first offspring built using the right-hand part of the first parent (i.e. the part including the extremity of the cross-section, point $P_{\text {end }}$ in Figure 8 ) and the left-hand part of the second parent (i.e. the part including the point on the axis of symmetry, point $P_{x}$ in Figure 8) as shown in Figure 8 and detailed in [30]. Elements constituting the offsprings are merged or subdivided to keep all elements about $4 \mathrm{~mm}$ long, in the interval [3 $\mathrm{mm}, 6 \mathrm{~mm}$. A typical cross-over probability of 0.8 is used.

\subsection{Mutation operator}

Mutation allows new cross-sectional shapes to be introduced in the population by redrawing a part or several parts of a cross-section. The operator is similar to the one presented in the companion paper [1], with the exceptions that (i) point $P_{x}$, on the axis of symmetry (see Figure 8), is always kept at the reference point $\left(x_{\max } / 4,0\right)$ to avoid duplicate cross-sections and (ii) if the end point $P_{\text {end, }}$ at the extremity of the cross-section (see Figure 8 ), is included in a mutated part, then a new end point $P_{\text {new end }}$ is defined at a random distance $d_{r}$ from the former point $P_{\text {end. }}$. The upper limit 
of $d_{r}$ is inversely proportional to the distance between $P_{\text {end }}$ and the mutated point. Point $P_{\text {new end }}$ allows cross-sections to be created with end points different from the ones of the initial population.

The mutation operator is detailed in [30].

\subsection{Augmented Lagrangian method}

The augmented Lagrangian method for GA described in Adeli and Cheng [33] is used in this study. The optimisation problem given in Eq. (1) is then expressed as,

$$
\text { Minimise } g=\frac{A}{A_{\text {squash }}}+\frac{1}{2} \gamma\left(\left|\frac{N^{*}}{N_{c}}-1\right|+\mu\right)^{2}
$$

Initial values for the Lagrangian coefficients of $\gamma=2$ and $\mu=0$ have been found to be appropriate values to ensure convergence of the algorithm [1], and are therefore used in the present work. A penalty increasing constant $\beta=1.05$ is used to avoid premature convergence of the algorithm at a convergence rate $\alpha=1.5$ [2,30]. Similar to the companion paper [1], to visualise the convergence of the algorithm, the fitness function $f$ in Eq. (1), with a constant penalty factor $\alpha$, is preferred through this paper.

\section{RESULTS}

This section presents the "optimum" singly-symmetric open cross-sections obtained for the 1,000 $\mathrm{mm}, 1,500 \mathrm{~mm}, 2,000 \mathrm{~mm}$ and 2,500 mm long columns. For each column length, 10 runs were performed with an initial population of 500 individuals. A maximum of 80 generations were analysed per run.

Figure 9 through Figure 12 plot the three fittest cross-sections and the tenth fittest cross-section out of the 10 runs at the $80^{\text {th }}$ generation for the $1,000 \mathrm{~mm}, 1,500 \mathrm{~mm}, 2,000 \mathrm{~mm}$ and $2,500 \mathrm{~mm}$ long columns, respectively. The fitness $f$ of the cross-sections is evaluated using Eq. (1) with a penalty 
factor $\alpha$ of 1.0. The entire design space is not plotted in Figure 9 through Figure 12 for clarity. All cross-sections found in this study are given in [30].

Table 2 summarises the optimum average cross-sectional areas $A_{\text {optimum }}$ and axial compression capacity $N_{c}$ after 10 runs. Likely due to the highly non-linear nature of the optimisation problem, the algorithm converges to slightly different cross-sectional shapes for each column length, as evident in Figure 9 through Figure 12. However, all 10 runs converge to similar values of cross-sectional areas, with coefficients of variation ranging from 0.004 to 0.008 as shown in Table 2 . The algorithm accurately satisfies the targeted axial capacity of $75 \mathrm{kN}$ with a maximum average coefficient of variation and error of 0.0023 and $0.21 \%$, respectively, for the $2,500 \mathrm{~mm}$ long column.

Figure 13 plots the average product between the fitness function $f$ (with a penalty factor $\alpha=1.0$ ) and $A_{\text {squash }} / A_{\text {optimum }}$ for each column length. The term $A_{\text {squash }} / A_{\text {optimum }}$ allows comparison between the fitness functions of columns of different lengths. Figure 13 shows that the algorithm converges to the "optimum" cross-sections in a relatively low number of generations, around 70 generations.

Figure 14 shows the evolution of the fittest cross-section for the $1,500 \mathrm{~mm}$ column shown in Figure 10 (a). The algorithm tends to smooth and close the profile through the optimisation process.

Table 3 gives the main properties of the fittest cross-sections shown Figure 9 (a), Figure 10 (a), Figure 11 (a) and Figure 12 (a) for the 1,000 mm, 1,500 mm, 2,000 mm and 2,500 mm long columns, respectively.

\section{DISCUSSION}

\subsection{General}

The cross-sections mainly converge to three different shape types, namely a "bean" shape (as in Figure 9 (a) through Figure 9 (c), or Figure 10 (c)), an "oval" shape (as in Figure 10 (a) and Figure 10 (b), Figure 11 (a) through Figure 11 (c), or Figure 12 (a)), and a rounded " $\Sigma$ " shape (as in Figure 
9 (d), Figure 10 (d), or Figure 12). The overall depth of the cross-sections is about $80 \mathrm{~mm}, 95 \mathrm{~mm}$, $110 \mathrm{~mm}$ and $120 \mathrm{~mm}$ for the $1,000 \mathrm{~mm}, 1,500 \mathrm{~mm}, 2,000 \mathrm{~mm}$ and $2,500 \mathrm{~mm}$ long columns, respectively.

Typically, the "oval" and "bean" cross-sections are like closed profiles, whereas as the " $\Sigma$ " crosssections tend to be open. Moreover, the "oval" and "bean" cross-sections usually behave better than the " $\Sigma$ " shape type cross-sections, with smaller cross-sectional areas.

On the other hand, the algorithm typically produces rounded cross-sectional shapes which have the advantages of (i) yielding high elastic local buckling stresses and (ii) maximising the second moments of area while minimising the cross-sectional area, as seen from the companion paper [1] Therefore, local buckling is never the dominant failure mode and the local member capacity $N_{c l}$ is always equal to the global member capacity $N_{c e}$ in Eq. (9).

Global buckling is typically the critical buckling mode for all "optimum" cross-sections with $N_{c}=$ $N_{c e}$ for 38 runs out of the total 40 runs. However, the algorithm optimises for both distortional and global buckling modes and the distortional nominal capacity $N_{c d}$ is on average equal to $76.05 \mathrm{kN}$ for the 40 runs, with a coefficient of variation of 0.025 , i.e. $1.4 \%$ higher than the targeted capacity of 75 $\mathrm{kN}$. Table 4 gives the average distortional nominal capacities $N_{c d}$ and elastic buckling loads $N_{o d}$ of the "optimum" columns for 10 runs. The close values between distortional and global buckling capacities are likely to generate buckling interaction between these two modes and therefore decrease the capacity $N_{c}$ of the cross-sections [23]. The distortional/global buckling interaction could be considered in the DSM by replacing $N_{y}$ by $N_{c e}$ when calculating the non-dimensional slenderness ratio $\lambda_{d}$ and in Eqs. (12) and (13), see [15, 17, 21].

Using the values of the elastic distortional buckling loads $N_{o d}$ in Table 4 and a value of $N_{c e}=75$ $\mathrm{kN}$ in the modified DSM equations for distortional/global interaction proposed in $[15,17,21]$ would result in an average capacity $N_{c}$ of the optimum cross-sections equal to $60.1 \mathrm{kN}, 55.3 \mathrm{kN}, 51.8 \mathrm{kN}$ and $50.6 \mathrm{kN}$ for the $1,000 \mathrm{~mm}, 1,500 \mathrm{~mm}, 2,000 \mathrm{~mm}$ and 2,500 mm long columns, respectively. This would correspond to a reduction in the axial capacity of $19.9 \%, 26.3 \%, 30.9 \%$ and $32.5 \%$ when compared to the targeted capacity of $75 \mathrm{kN}$ for the $1,000 \mathrm{~mm}, 1,500 \mathrm{~mm}, 2,000 \mathrm{~mm}$ and $2,500 \mathrm{~mm}$ long columns, respectively. The distortional/global buckling interaction is therefore likely to 
considerably reduce the axial capacity of the cross-sections, and it is important to consider this effect (outside the scope of this paper) by (i) forcing the algorithm to avoid buckling mode interactions, (ii) considering this interaction in the DSM equations or (iii) using other method to determine the capacity of the cross-sections, such as advanced finite element analysis. The latter may be currently too computationally intensive.

\subsection{Manufacturing processes}

Current cold-forming processes, such as roll-forming and brake-pressing, have limited ability to form continuously curved surfaces without discrete bends. Therefore, the "optimum" cross-sections found in this paper cannot currently be manufactured as they are. In a first attempt to consider the manufacturing constraints in the optimisation process, the "optimum" cross-sections are manually redrawn using straight lines and a limited number of bends. Stiffeners used to avoid local instabilities are considered in redrawing the cross-sections. The cross-sections presented in Figure

9 (c), Figure 10 (a), Figure 11 (b) and Figure 12 (b) for column lengths of 1,000 mm, 1,500 mm, $2,000 \mathrm{~mm}$ and $2,500 \mathrm{~mm}$, respectively, are selected for redrawing. The redrawn cross-sections are shown in Figure 15.

Table 5 gives the cross-sectional areas and axial capacities $N_{c}$, calculated using the rules given in Section 3, of the "redrawn" cross-sections. The difference in cross-sectional area and axial capacity when compared to the "optimum" cross-sections are also given in Table 5.

Table 5 shows that the first attempt to manually redraw the optimum cross-sections to allow rollforming and brake-pressing processes, gives reasonable results. When compared to the raw "optimum" cross-sections, the cross-sectional areas increase by less than $2 \%$ while the axial capacities only decrease by $1 \%$ to $2 \%$. 


\section{FUTURE RESEARCH}

The self-shape optimisation principle will be extended in the future to incorporate the moment capacity $M_{c}$ estimated from the DSM in the fitness function $f$, in a similar manner to the axial capacity $N_{c}$ (see Section 2).

The final aim of this study is to optimise cross-sections for practical industrial uses, and the limitations of cold-forming processes will be added to the algorithm. In addition to the manufacturing constraints, construction constraints specific to various types of cold-formed steel applications, such as purlins or girts, will be also added to the algorithm.

As discussed in Section 6.1, the algorithm optimises for distortional and global buckling, and the buckling mode interaction will need to be taken into account in the optimisation process.

\section{CONCLUSIONS}

The extension of the self-shape optimisation method introduced in the companion paper to strength optimisation of singly-symmetric open cold-formed steel columns has been presented. The Direct Strength Method (DSM) as specified in AS/NZS 4600 Cold-formed Steel Structures was used to determine the axial member capacity $N_{c}$ of the columns. Rules to automatically select the elastic local and distortional buckling stresses from the Finite Strip and constrained Finite Strip analyses have been discussed and validated against 48 conventional and 12 "optimum" cold-formed steel sections yielded in the present work.

Columns with a wall thickness of $1.2 \mathrm{~mm}$, lengths varying from $1,000 \mathrm{~mm}$ to $2,500 \mathrm{~mm}$ and subjected to an axial compressive load of $75 \mathrm{kN}$ were optimised. The cross-sections converged to "bean", "oval" or rounded " $\Sigma$ " shape types, in a relatively low number of generations, around 70 generations. The rounded shapes have the advantages of increasing the local buckling strength while maximising the global buckling strength. The algorithm mainly optimises the cross-sections for 
distortional and global buckling, which may lead to distortional/global buckling interaction, currently not considered in the DSM.

A manual attempt to redraw the raw "optimum" cross-sections with straight lines in order to include the current limitations of cold-forming processes was made. The performance of the redrawn cross-sections was found to be close to the raw "optimum" cross-sections.

\section{ACKNOWLEDGMENT}

The authors would like to thank Emeritus Professor Gregory Hancock, The University of Sydney, for his guidance in developing the rules for determining the local and distortional buckling stresses.

\section{REFERENCES}

[1] B.P. Gilbert, L.H. Teh, H. Guan, Self-shape optimisation principles: Optimisation of section capacity for thin-walled profiles, Thin-Walled Structures, (Submitted) (2012).

[2] B.P. Gilbert, L.H. Teh, H. Guan, Self-shape optimisation of cold-formed steel closed profiles using Genetic Algortihm Research Report CIEM/2011/R01, Centre for Infrastructure Engineering and Management, Griffith University, Australia, 2011.

[3] Y.K. Cheung, Finite Strip Method in structural analysis, Pergamon Press, Inc., New York, N.Y., 1976

[4] R.J. Plank, W.H. Wittrick, Buckling under combined loading of thin, flat-walled structures by a complex Finite Strip Method, International Journal for Numerical Methods in Engineering, 8 (1974) 323-329.

[5] J.S.D. Przmieniecki, Finite Element structural analysis of local instability, Journal of the American Institute of Aeronautics and Austronautics, 11 (1973) 33-39. 
[6] S. Adany, B.W. Schafer, A full modal decomposition of thin-walled, single-branched open crosssection members via the constrained finite strip method, Journal of Constructional Steel Research, 64 (2008) 12-29.

[7] S. Adany, B.W. Schafer, Buckling mode decomposition of single-branched open cross-section members via finite strip method: Derivation, Thin-Walled Structures, 44 (2006) 563-584.

[8] S. Adany, B.W. Schafer, Buckling mode decomposition of single-branched open cross-section members via finite strip method: Application and examples, Thin-Walled Structures, 44 (2006) 585600.

[9] B.W. Schafer, S. Adany, Buckling analysis of cold-formed steel members using CUFSM: conventional and constrained finite strip methods, in: R.A. LaBoule, W.W. Yu (Eds.) 18th International Specialty Conference on Cold-Formed Steel Structures, Orlando, Florida, U.S.A., 2006, pp. 39-54.

[10] AS/NZS 4600, Cold-formed steel structures, Standards Australia, Sydney, Australia, 2005.

[11] B.W. Schafer, T. Pekoz, Direct Strength prediction of cold-formed steel members using numerical elastic buckling solutions, in: W.W. Yu, R.A. LaBoule (Eds.) 14th International Specialty Conference on Cold-Formed Steel Structures St Louis, Missouri, U.S.A., 1998, pp. 69-76.

[12] B.W. Schafer, Designing cold-formed steel using the direct strength method, in: R.A. LaBoule, W.W. Yu (Eds.) 18th International Specialty Conference on Cold-Formed Steel Structures Orlando, Florida, 2006, pp. 475-490.

[13] AISI, Direct Strength Method (DSM) design guide, Washington D.C., U.S.A., 2006.

[14] AISI, North American Specification for the Design of Cold-formed Steel Structural Members 2007 Edition, American Iron and Steel Institute, Washington D.C., U.S.A., 2007.

[15] G.J. Hancock, Design of cold-formed steel structures (to AS/NZ 4600:2007) - 4th Edition, Australian Steel Institute, North Sydney, Australia, 2007.

[16] G. Thierauf, Thin-Walled Structures and Realted Optimisation Problems, Thin-Walled Structures, 9 (1990) 241-246. 
[17] D.M. Yang, G.J. Hancock, Compression tests of high strength steel channel columns with interaction between local and distortional buckling, ASCE Journal of Structural Engineering, 130 (2004) 1954-1963.

[18] Y.B. Kwon, B.S. Kim, G.J. Hancock, Compression tests of high strength cold-formed steel channels with buckling interaction, Journal of Constructional Steel Research, 65 (2009) 278-289.

[19] P.B. Dinis, D. Camotim, N. Silvestre, FEM-based analysis of the local-plate/distortional mode interaction in cold-formed steel lipped channel columns, Comput. Struct., 85 (2007) 1461-1474.

[20] N. Silvestre, D. Camotim, P.B. Dinis, Direct Strength prediction of lipped channel columns experiencing local-plate/distortional interaction, Advanced Steel Construction, 5 (2009) 49-71.

[21] N. Silvestre, P.B. Dinis, D. Camotim, E.M. Batista, DSM design of lipped channel columns undergoing local/distortional/global mode interaction, in: E. Bastita, P. Vellasco, L. de Lima (Eds.) Stability and Ductility of Steel Structures, Rio de Janeiro, Brazil, 2010, pp. 1061-1068.

[22] B.W. Schafer, Local, distortional, and Euler buckling of thin-walled columns, ASCE Journal of Structural Engineering, 128 (2002) 289-299.

[23] P.B. Dinis, D. Camotim, Post-buckling behaviour and strength of cold-formed steel lipped channel columns experiencing distortional/global interaction, Comput. Struct., 89 (2011) 422-434. [24] D.C.Y. Yap, G.J. Hancock, Experimental Study of High-Strength Cold-Formed Stiffened-Web C-Sections in Compression, ASCE Journal of Structural Engineering, 137 (2011) 162-172.

[25] D.C.Y. Yap, G.J. Hancock, Experimental Study of Complex High-Strength Cold-Formed CrossShaped Steel Section, ASCE Journal of Structural Engineering, 134 (2008) 1322-1333.

[26] B.W. Schafer, Review: The Direct Strength Method of cold-formed steel member design, Journal of Constructional Steel Research, 64 (2008) 766-778.

[27] Z. Li, B.W. Schafer, Application of the finite strip method in cold-formed steel member design, Journal of Constructional Steel Research, 66 (2010) 971-980.

[28] J. Leng, J.K. Guest, B.W. Schafer, Shape optimization of cold-formed steel columns, ThinWalled Structures, 49 (2011) 1492-1503.

[29] Z. Li, B.W. Schafer, Buckling analysis of cold-formed steel members with general boundary conditions using CUFSM: conventional and constrained finite strip methods, in: R.A. LaBoule, W.W. 
Yu (Eds.) 20th International Specialty Conference on Cold-Formed Steel Structures St Louis, Missouri, 2010.

[30] T.J.-M. Savoyat, B.P. Gilbert, L.H. Teh, Self-shape optimisation of cold-formed steel columns, Research Report CIEM/2012/R01, Centre for Infrastructure Engineering and Management, Griffith University, Australia, 2012.

[31] G.J. Hancock, Distortional buckling of steel storage rack columns, ASCE Journal of Structural Engineering, 111 (1985) 2770-2783.

[32] BlueScope Lysaght, The Lysaght referee, 32nd Edition, BlueScope Steel Limited, 2009.

[33] H. Adeli, N.-T. Cheng, Augmented Lagrangian Genetic Algorithm for Structural Optimization, Journal of Aerospace Engineering, 7 (1994) 104-118. 


\begin{tabular}{|c|c|c|c|c|c|c|c|c|c|}
\hline \multirow[b]{3}{*}{ Section type } & \multirow{3}{*}{$\begin{array}{c}\mathrm{Nb} \text {. of } \\
\text { section } \\
\text { analysed }\end{array}$} & \multirow{2}{*}{\multicolumn{2}{|c|}{ Depth / Thickness }} & \multicolumn{6}{|c|}{$\begin{array}{c}\text { Difference in elastic buckling stresses relative to the } \\
\text { manual method }(\%)^{(1)}\end{array}$} \\
\hline & & & & \multicolumn{3}{|c|}{ Local } & \multicolumn{3}{|c|}{ Distortional } \\
\hline & & Min & $\operatorname{Max}$ & Average & Min & Max & Average & Min & $\operatorname{Max}$ \\
\hline Cee & 16 & 52.6 & 133.3 & 0.0 & 0.0 & 0.0 & 0.6 & 0.0 & 2.2 \\
\hline Zed & 16 & 52.6 & 133.3 & 0.0 & 0.0 & 0.0 & 0.6 & 0.0 & 3.8 \\
\hline Rack with lip stiff. & 9 & 22.9 & 60.0 & 0.0 & 0.0 & 0.0 & -2.8 & -8.1 & 0.0 \\
\hline Rack w/o lip stiff. & 7 & 22.9 & 60.0 & -1.9 & -8.6 & 0.0 & 0.0 & 0.0 & 0.0 \\
\hline Optimum & 12 & 66.6 & 100.0 & 0.7 & -2.1 & 4.7 & 0.7 & 0.0 & 2.6 \\
\hline All cross-sections & 60 & 22.9 & 133.3 & -0.08 & -- & -- & 0.03 & -- & -- \\
\hline
\end{tabular}

Table 1: Comparison between manual method and automated rules

\begin{tabular}{c|cc|ccc}
$\begin{array}{c}\text { Column length } \\
(\mathrm{mm})\end{array}$ & \multicolumn{2}{|c|}{ Cross-section area } & \multicolumn{3}{c}{ Average axial capacity } \\
\hline 1,000 & Average $\left(A_{\text {optimum }}\right)\left(\mathrm{mm}^{2}\right)$ & CoV & Average $(\mathrm{kN})$ & CoV & Error $(\%)$ \\
1,500 & 242.1 & 0.0042 & 74.84 & 0.0023 & 0.21 \\
2,000 & 288.7 & 0.0043 & 74.91 & 0.0015 & 0.12 \\
2,500 & 337.8 & 0.0037 & 74.92 & 0.0013 & 0.11 \\
& 388.4 & 0.0078 & 74.98 & 0.0008 & 0.05
\end{tabular}

Table 2: Average cross-sectional area and axial capacity at the $80^{\text {th }}$ generation

\begin{tabular}{c|cccccc}
$\begin{array}{c}\text { Column } \\
\text { length }(\mathrm{mm})\end{array}$ & $A\left(\mathrm{~mm}^{2}\right)$ & $I_{x}\left(\mathrm{~mm}^{4}\right)$ & $I_{y}\left(\mathrm{~mm}^{4}\right)$ & $C_{w}\left(\mathrm{~mm}^{6}\right)$ & $J\left(\mathrm{~mm}^{4}\right)$ & $x_{\text {os }}(\mathrm{mm})$ \\
\hline 1,000 & 240.5 & 173,055 & 62,273 & $2.511 \times 10^{8}$ & 115 & 44.8 \\
1,500 & 287.2 & 286,004 & 112,652 & $6.744 \times 10^{8}$ & 138 & 53.5 \\
2,000 & 336.8 & 444,174 & 183,051 & $1.460 \times 10^{9}$ & 162 & 60.8 \\
2,500 & 385.8 & 705,426 & 277,973 & $2.655 \times 10^{9}$ & 185 & 66.9
\end{tabular}

Table 3: Main properties of the optimum cross-sections

\begin{tabular}{c|ccc} 
Column length $(\mathrm{mm})$ & $N_{c d}(\mathrm{kN})$ & $N_{c d}$ CoV & $N_{o d}(\mathrm{kN})$ \\
\hline 1,000 & 75.12 & 0.008 & 89.0 \\
1,500 & 75.08 & 0.003 & 71.8 \\
2,000 & 75.53 & 0.006 & 61.6 \\
2,500 & 78.49 & 0.032 & 58.2
\end{tabular}

Table 4: Average distortional nominal capacities $N_{c d}$ and elastic buckling loads $N_{o d}$

\begin{tabular}{c|cc|cc} 
Column length $(\mathrm{mm})$ & Area $\left(\mathrm{mm}^{2}\right)$ & Diff. with optimum $(\%)$ & Nc $(\mathrm{kN})$ & Diff. with optimum (\%) \\
\hline 1,000 & 244.7 & 1.32 & 74.2 & 0.80 \\
1,500 & 289.7 & 0.87 & 73.8 & 1.20 \\
2,000 & 340.3 & 1.01 & 74.4 & 0.80 \\
2,500 & 392.6 & 1.63 & 73.4 & 2.13
\end{tabular}

Table 5: Cross-sectional areas and axial nominal capacities $N_{c}$ of the "optimum" cross-sections redrawn with straight lines 


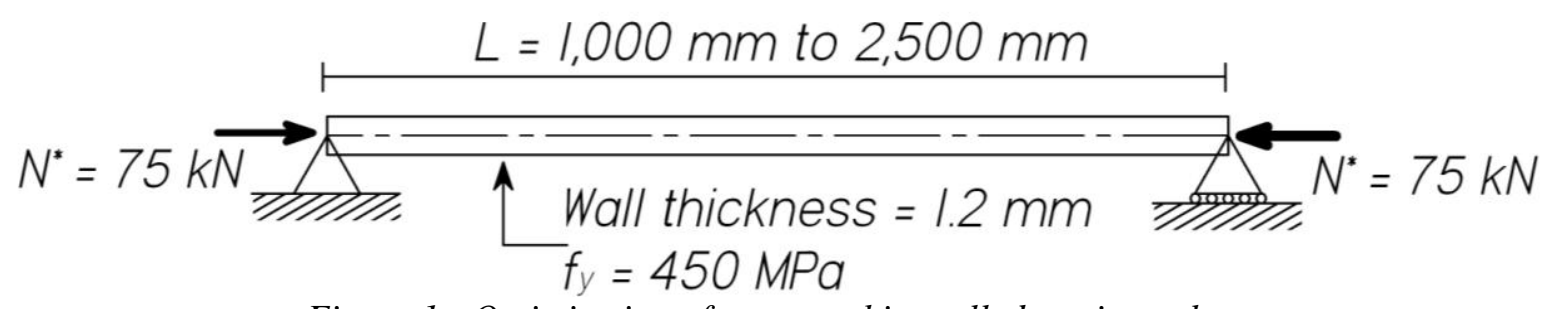

Figure 1 : Optimisation of an open thin-walled section column

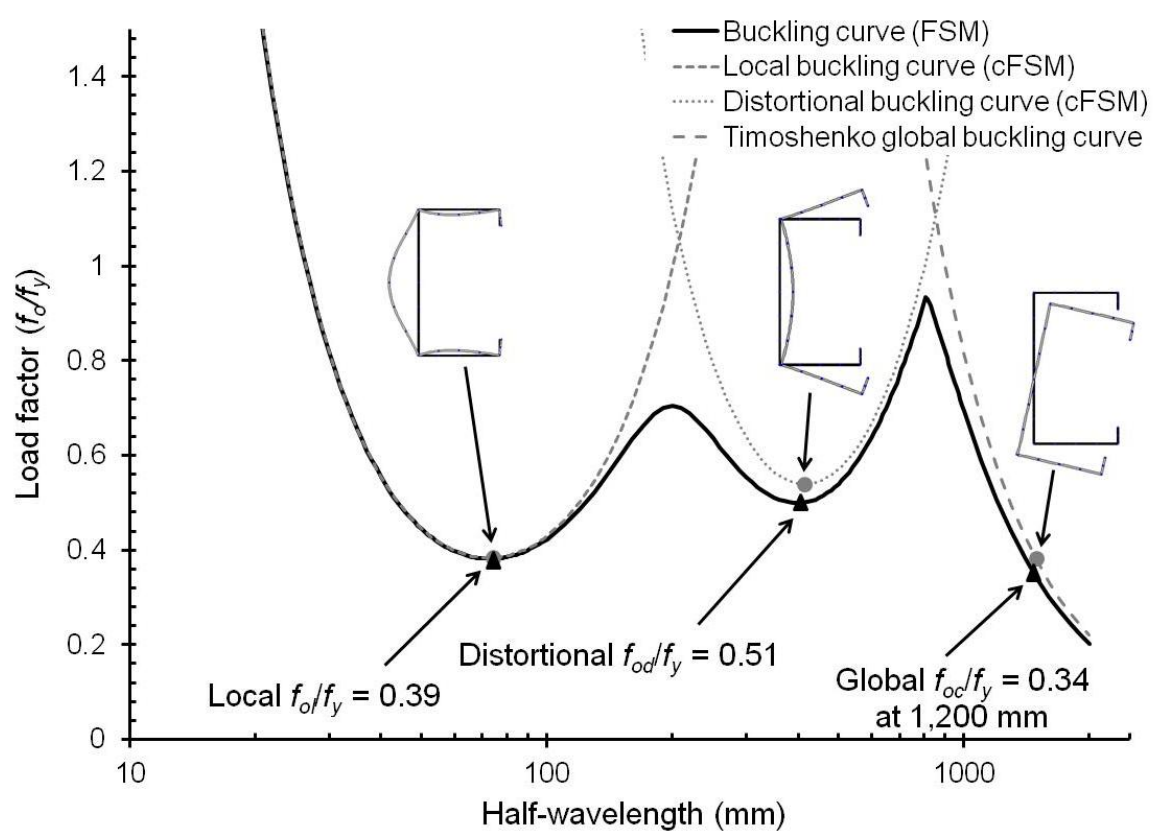

Figure 2: Signature curve and mode decomposition for a C9012 lipped Cee-section

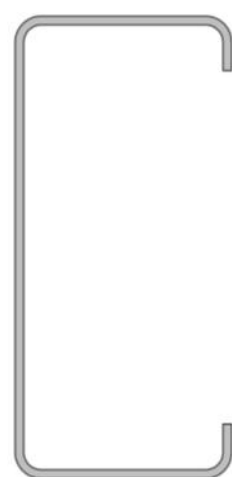

(a)

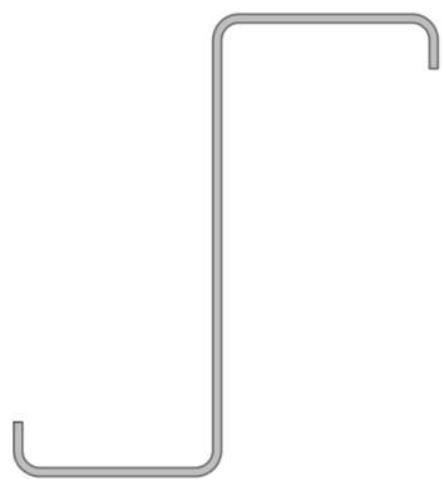

(b)

Figure 3: (a) Cee-section and (b) Zed-section 


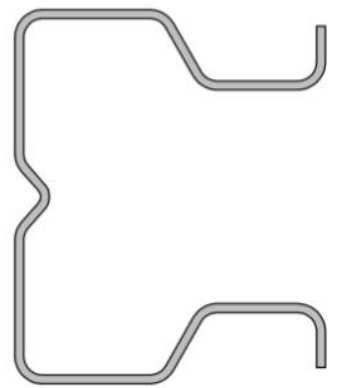

(a)

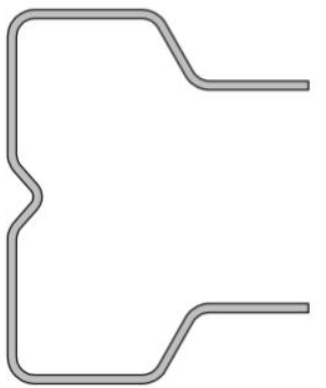

(b)

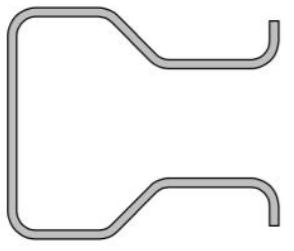

(c)

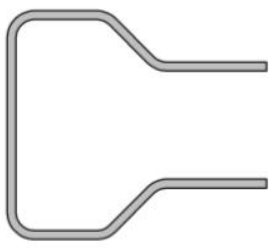

(d)

Figure 4: Typical storage rack uprights (a) with web and lip stiffeners, $(b)$ with web stiffener only, (c) with lip stiffener only and $(d)$ without web and lip stiffeners.

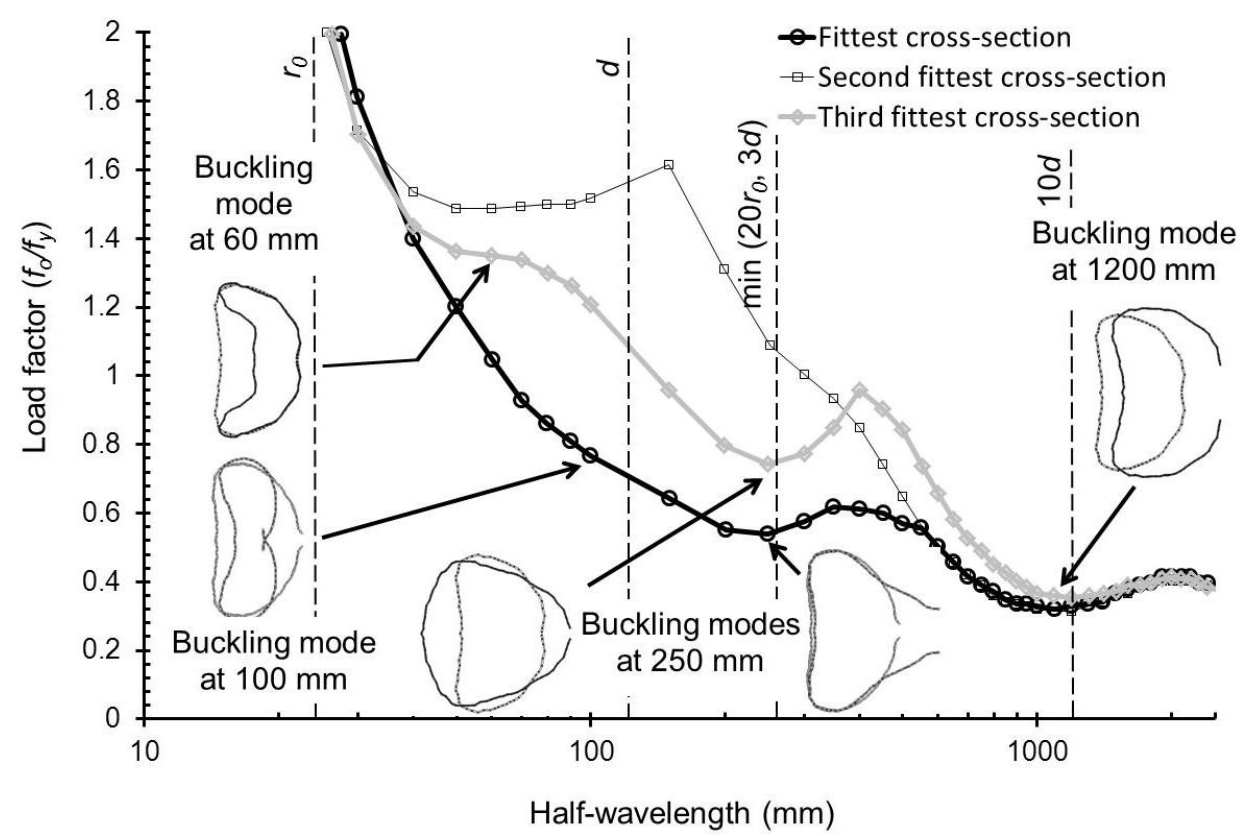

Figure 5: Buckling curves for the three fittest 2,500 mm long columns

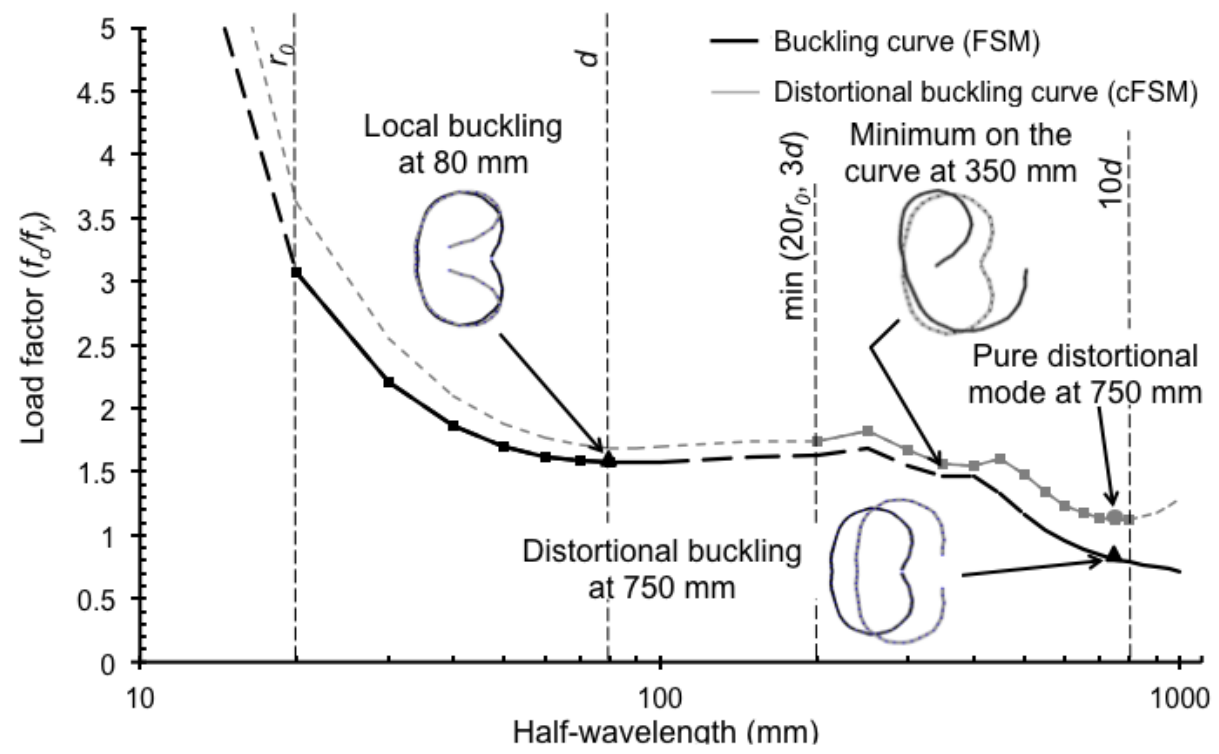

Figure 6: Buckling curve for the second fittest 1,000 $\mathrm{mm}$ long column 


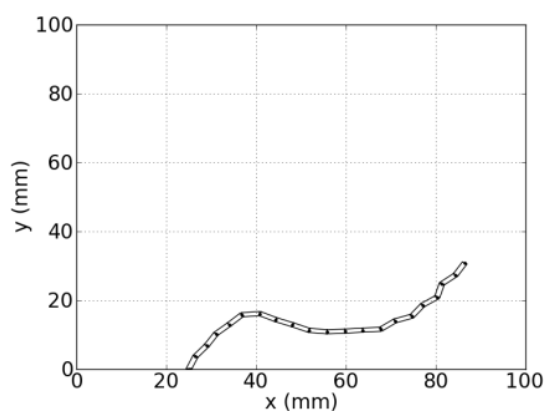

(a)

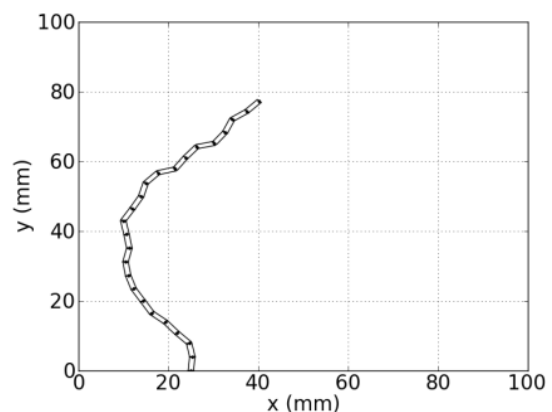

(b)

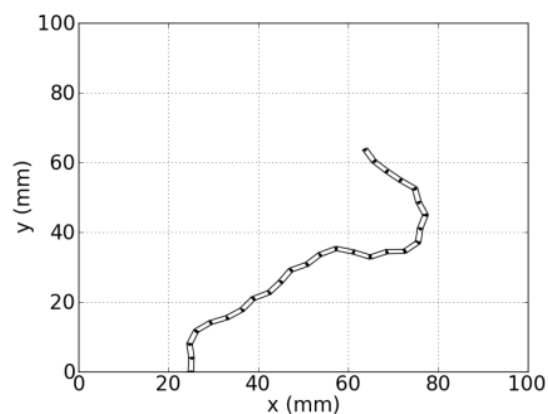

(c)

Figure 7: Example of initial cross-sections on a $100 \mathrm{~mm} \times 100 \mathrm{~mm}$ design space of (a) 41 elements, (b) 49 elements and (c) 53 elements

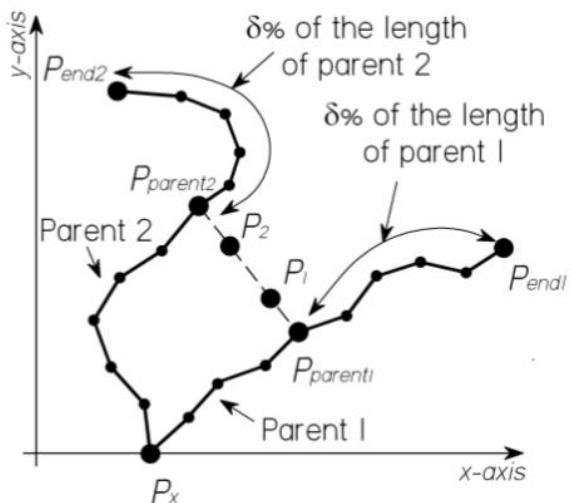

(a)

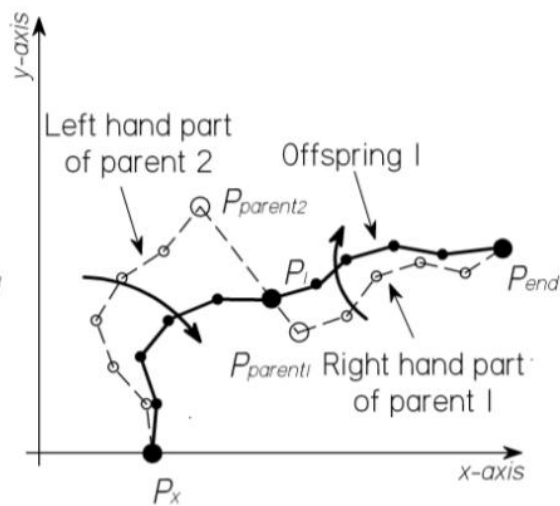

(b)

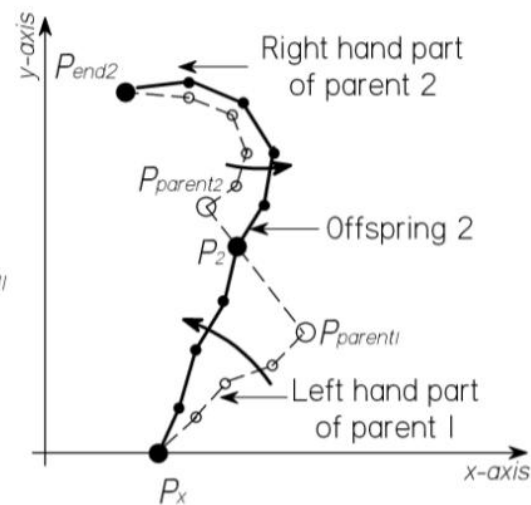

(c)

Figure 8: Cross-over operator (a) defining cross-over points, $(b)$ creation of the first offspring and (c) creation of the second offspring 


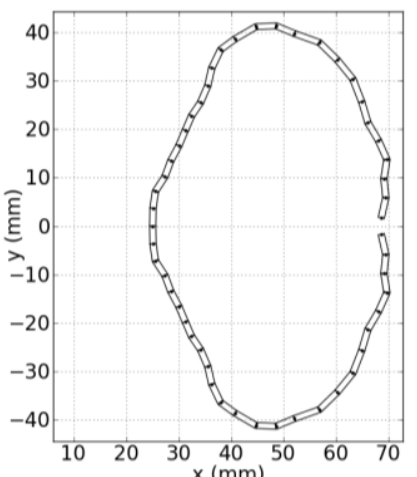

(a) $-A=240.5 \mathrm{~mm}^{2}$, $N_{c}=74.8 \mathrm{kN}$

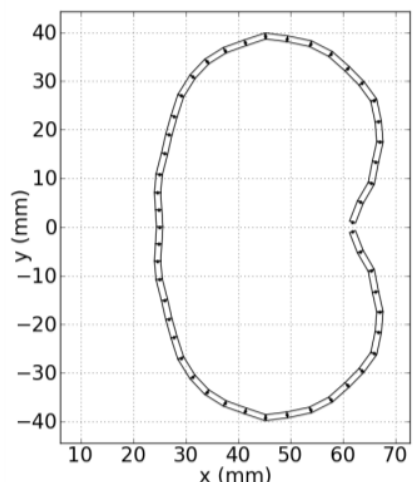

(b) $-A=241.2 \mathrm{~mm}^{2}$, $N_{c}=74.9 \mathrm{kN}$

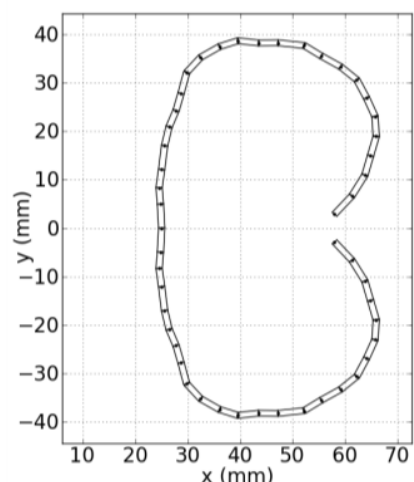

(c) $-A=241.5 \mathrm{~mm}^{2}$, $N_{c}=74.8 \mathrm{kN}$

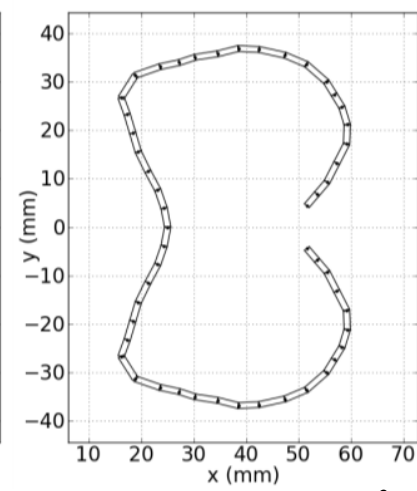

(d) $-A=243.8 \mathrm{~mm}^{2}$, $N_{c}=74.9 \mathrm{kN}$

Figure 9: "Optimum" cross-sections for a column length of 1,000 mm in increasing fitness order from (a) fittest cross-section, (b) second fittest cross-section, (c) third fittest cross-section and (d) tenth fittest crosssection

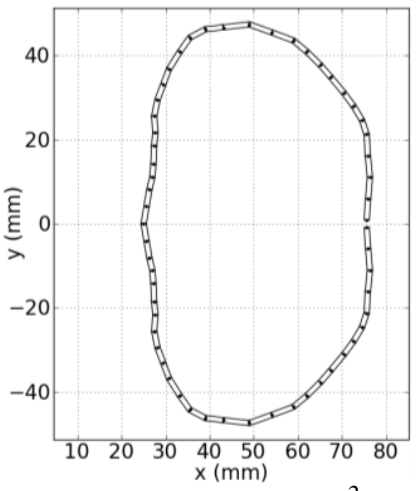

(a) $-A=287.2 \mathrm{~mm}^{2}$,

$N_{c}=74.7 \mathrm{kN}$

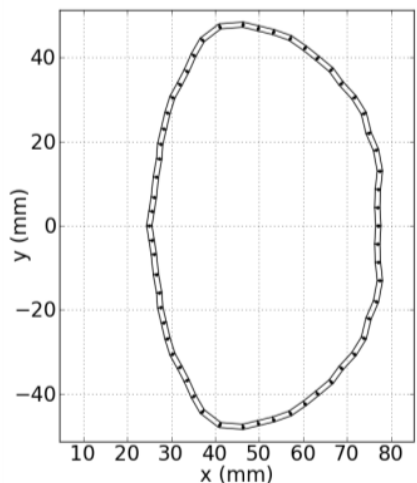

(b) $-A=287.8 \mathrm{~mm}^{2}$,

$N_{c}=75.0 \mathrm{kN}$

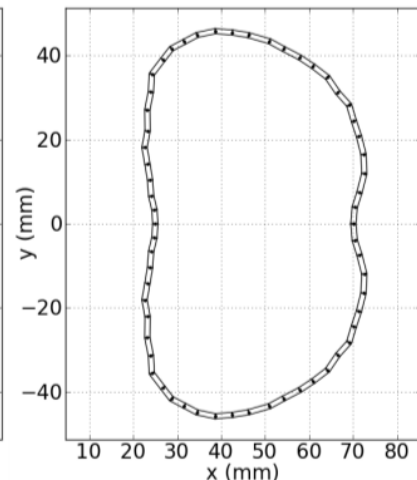

(c) $-A=287.6 \mathrm{~mm}^{2}$, $N_{c}=74.8 \mathrm{kN}$

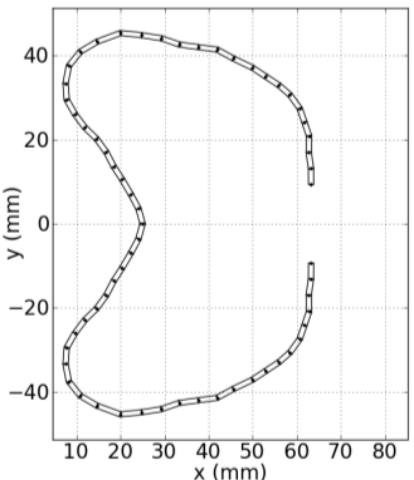

(d) $-A=291.4 \mathrm{~mm}^{2}$ $N_{c}=74.8 \mathrm{kN}$

Figure 10: "Optimum" cross-sections for a column length of 1,500 $\mathrm{mm}$ in increasing fitness order from (a) fittest cross-section, (b) second fittest cross-section, (c) third fittest cross-section and (d) tenth fittest crosssection

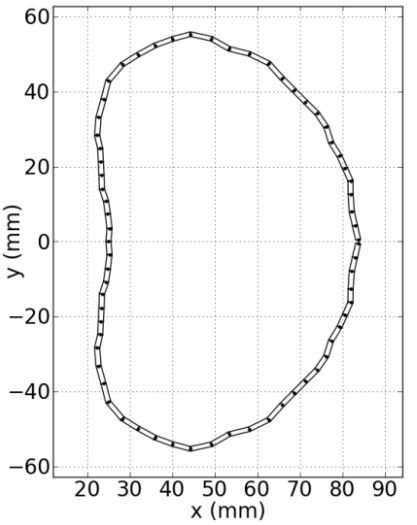

(a) $-A=336.8 \mathrm{~mm}^{2}$,

$$
N_{c}=75.0 \mathrm{kN}
$$

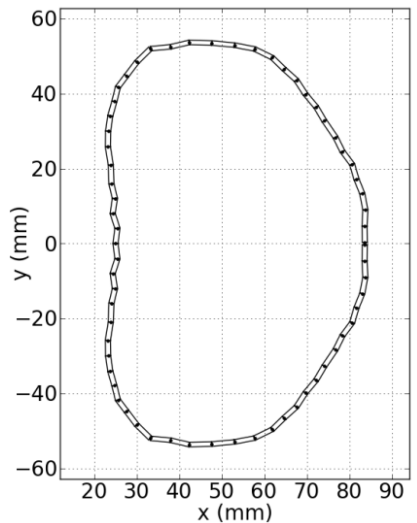

(b) $-A=336.8 \mathrm{~mm}^{2}$, $N_{c}=75.0 \mathrm{kN}$

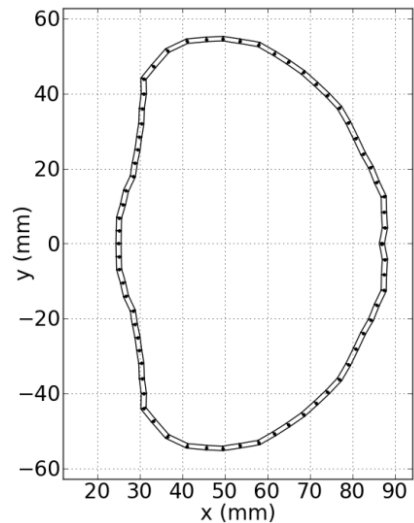

(c) $-A=336.9 \mathrm{~mm}^{2}$, $N_{c}=75.0 \mathrm{kN}$

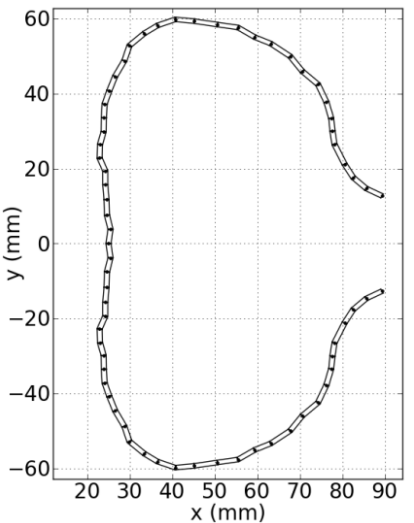

(d) $-A=340.5 \mathrm{~mm}^{2}$, $N_{c}=74.8 \mathrm{kN}$

Figure 11: "Optimum" cross-sections for a column length of 2,000 $\mathrm{mm}$ in increasing fitness order from (a) fittest cross-section, (b) second fittest cross-section, (c) third fittest cross-section and (d) tenth fittest cross- 


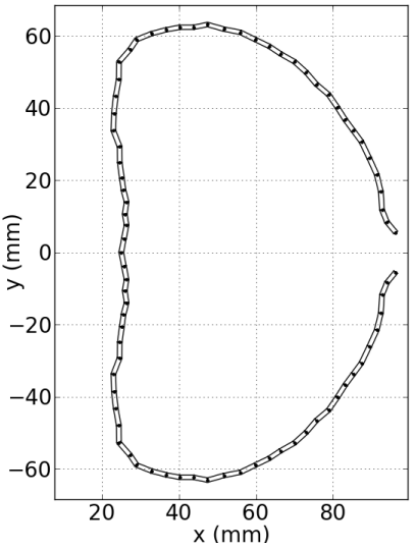

(a) $-A=385.8 \mathrm{~mm}^{2}$

$N_{c}=74.9 \mathrm{kN}$

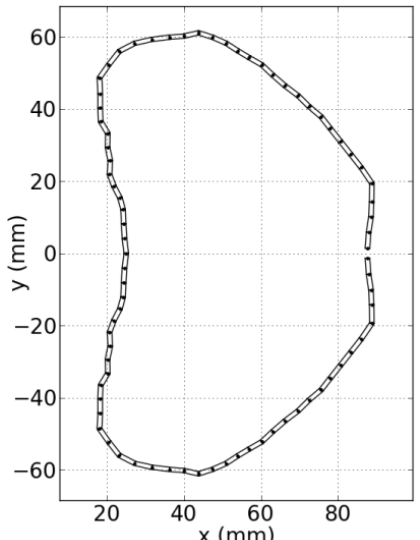

(b) $-A=386.3 \mathrm{~mm}^{2}$, $N_{c}=75.0 \mathrm{kN}$

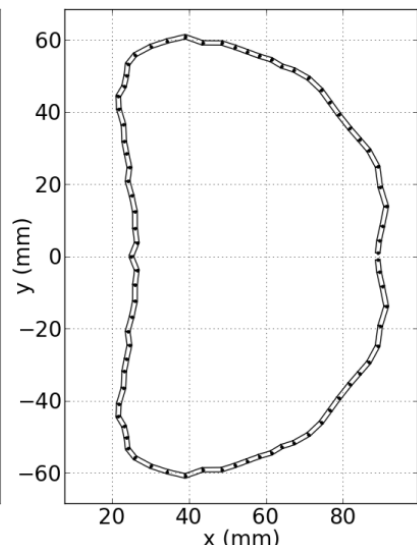

(c) $-A=386.8 \mathrm{~mm}^{2}$, $N_{c}=75.0 \mathrm{kN}$

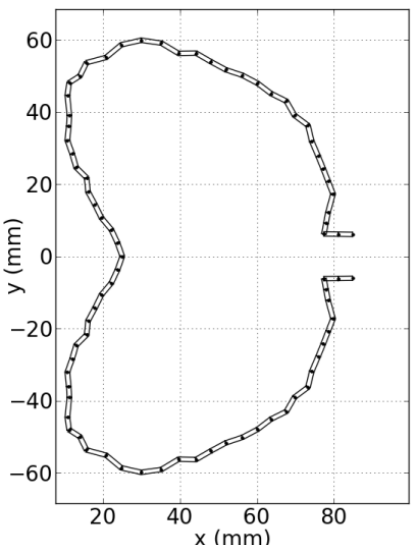

(d) $-A=396.4 \mathrm{~mm}^{2}$, $N_{c}=75.0 \mathrm{kN}$

Figure 12: "Optimum" cross-sections for a column length of 2,500 $\mathrm{mm}$ in increasing fitness order from (a) fittest cross-section, (b) second fittest cross-section, (c) third fittest cross-section and (d) tenth fittest crosssection

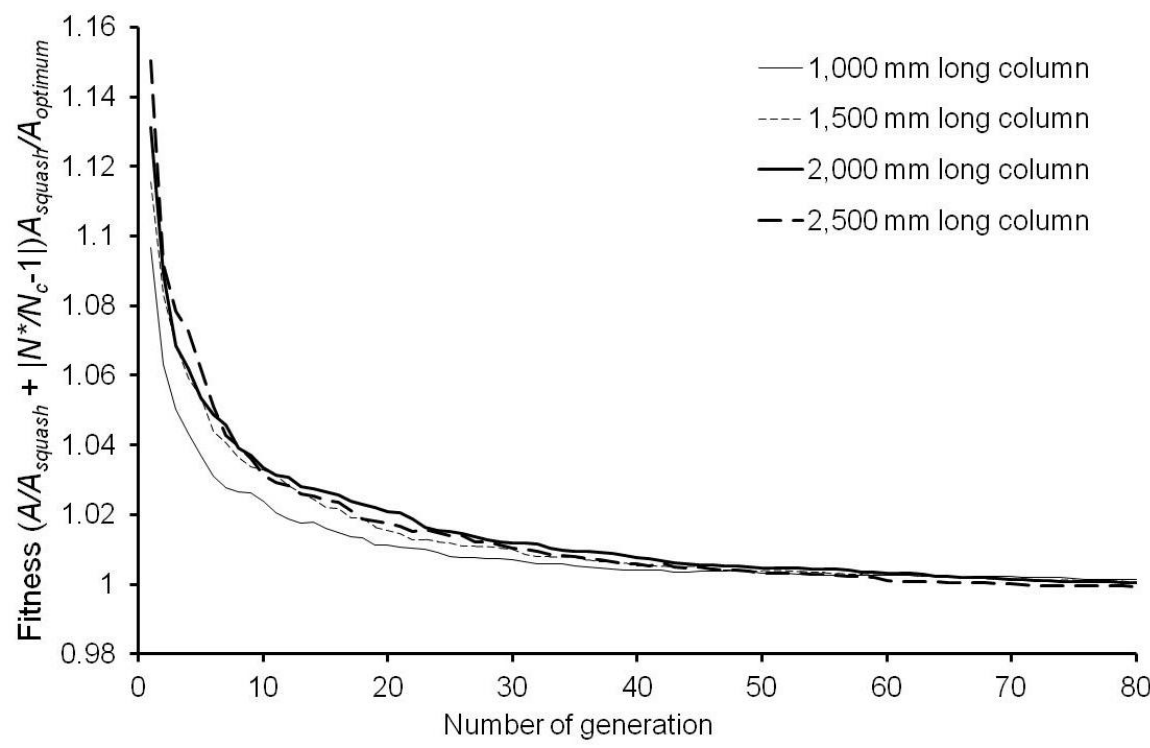

Figure 13: Evolution of the average fitness for 10 runs for each column length 

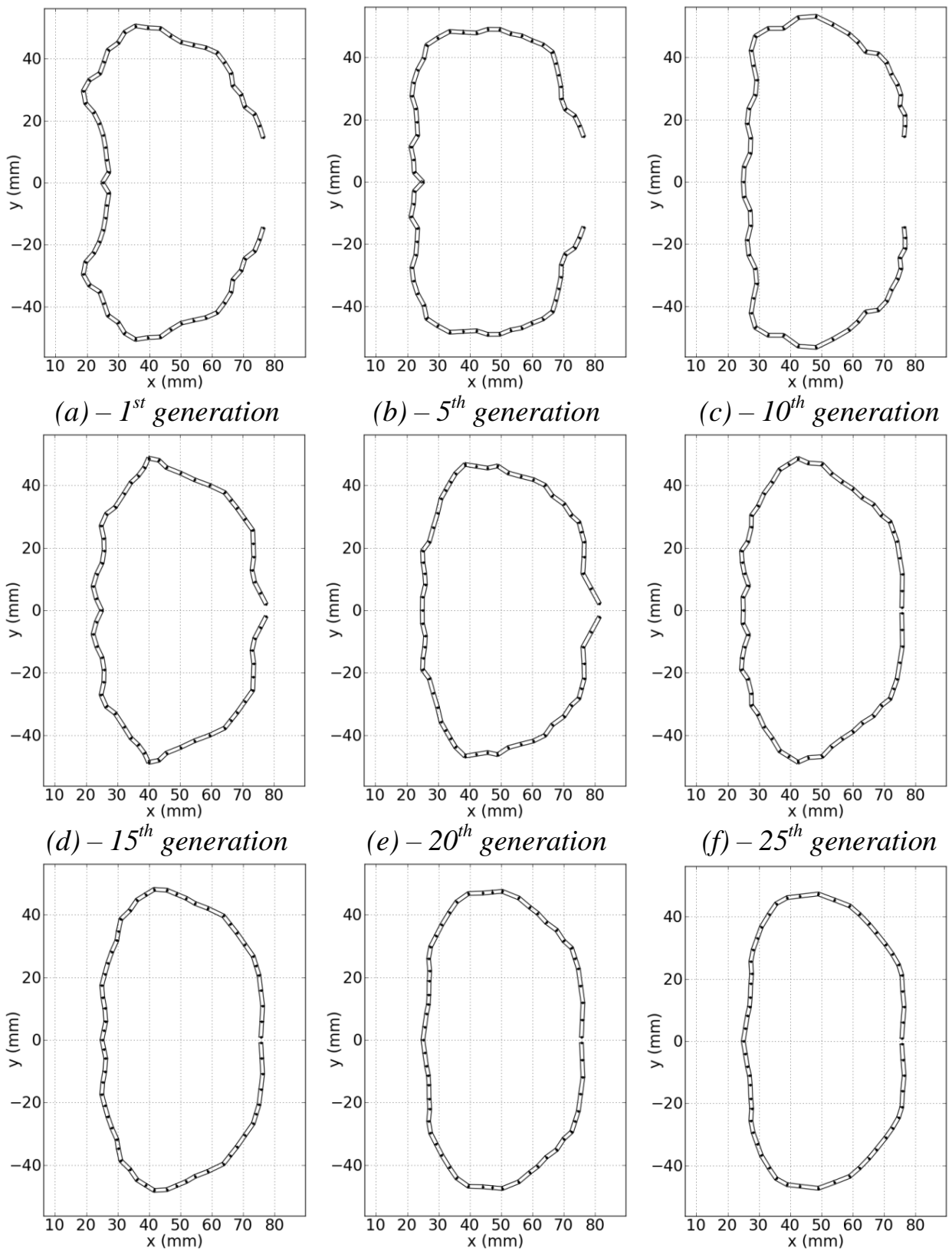

$(g)-40^{\text {th }}$ generation
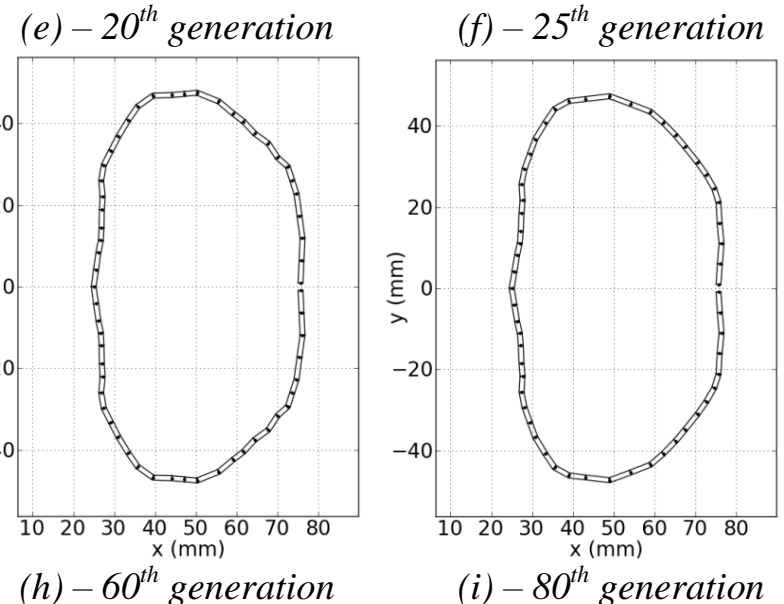

Figure 14: Evolution of the optimum cross-section in Figure 10 (a) from (a) $1^{\text {st }}$ generation (initial population) to (i) $80^{\text {th }}$ generation (last generation) 


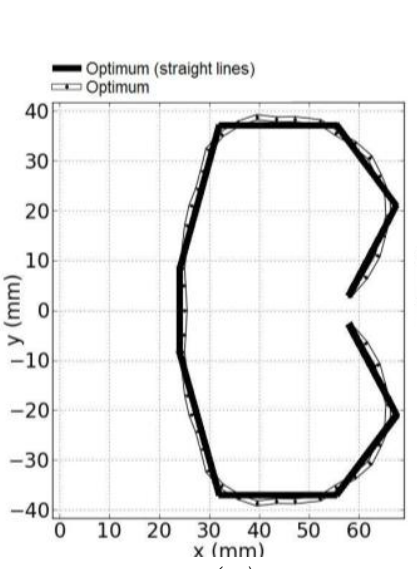

(a)

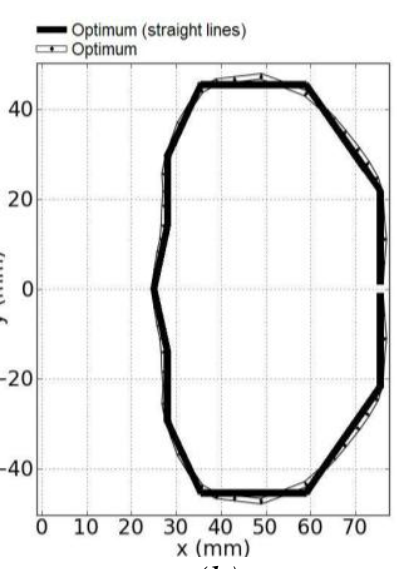

(b)

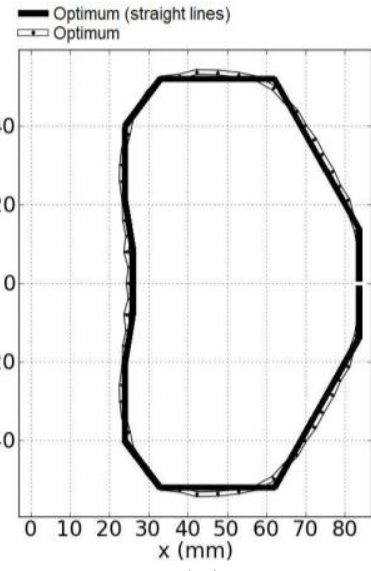

(c)

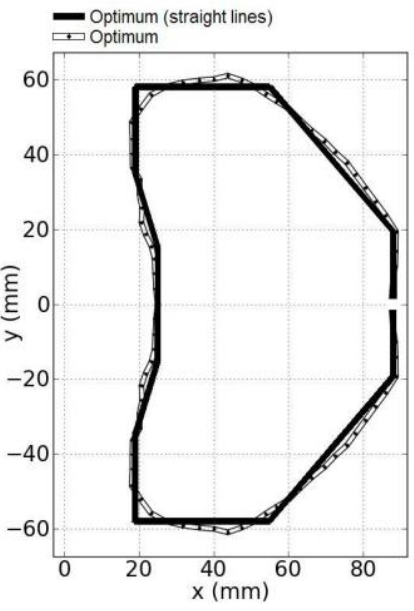

(d)

Figure 15: "Optimum" cross-sections redrawn with straight lines for column lengths of (a) 1,000 mm, (b) $1,500 \mathrm{~mm}$, (c) 2,000 $\mathrm{mm}$ and (d) $2,500 \mathrm{~mm}$ 